\title{
On the College Public Network Opinion Supervision with the Perspective of Media Literacy
}

\author{
Li-min ZHANG ${ }^{1}$,Xiao-pu WANG ${ }^{2}$,Qiu-ying SONG ${ }^{3}$ \\ ${ }^{1}$ Humanities and Social Science of Agricultural University of Hebei, Baoding, China \\ ${ }^{2}$ Registrar's Office of The Central Institute For Correctional Police Baoding, China \\ ${ }^{3}$ The Central Institute For Correctional Police Baoding, China
}

\begin{abstract}
With the continuous development of information technology, the network has become the important means of communication and information for college students. Compared with the ordinary social network public opinion, the university network public opinion has more features, and reflects the current state of mind of college students. By analyzing its present condition and characteristics, and with the perspective of media literacy, there are many effective means to improve the university network public opinion supervision, to guide students to set up the correct outlook on life values, to strengthen the ideological and political education effect.
\end{abstract}

Keywords: Media literacy; the universities; public opinion supervision

\section{INTRODUCTION}

In terms of media literacy education in our country, it is really imported. At present, we often refer to the definition of media literacy program files from Canada Ontario ministry of education in 1989, in the media literacy resource guide to the definition of media literacy, namely "media literacy aims to cultivate students' nature of mass media, media commonly used skills and means as well as the effect of these techniques and methods of cognition and judgment."[1] With the rapid development of Internet technology, represented by college students most of the young people get used to collecting information on the Internet communication, they look for some social hot spots or campus content is closely related to their own lives having their own ideas, and will choose to express these ideas through the network.

Relating to the definition of network public opinion in colleges and universities, we generally will be limited in the colleges and universities. The main of people is college students and teachers, who published their speech with a certain tendency, for some hot issues on the network, and there are a certain number of people in the discussion, have formed a certain influential common opinions or comments. In the article published Pan Qingquan, Wei Huim in discuss about the characteristics of university network public opinion, influence and effective use of, they define it as "inside and outside the university network public opinion is mainly refers to college students in the school by a variety of events, and spread with the help of the Internet, and within the scope of the colleges and universities form for exciting event of cognition, attitude, emotion and behavioral tendency of collections."[2]

The content of the university network public opinion is roughly divided into two categories. The First is the social class, which aimed at all kinds of social news are discussed, such as the Wen Chuan earthquake, or the party's 18th at the universal social influence of the content. Accepted the higher education of our country's talents, focusing on the social hot spot, college students have important embodiment of social responsibility on their shoulders. The second class is campus. This category is more about the campus life, about all aspects of the students' school life, such as grants, and exam etc. In colleges and universities the atmosphere for everyone is closely related to its own development of the topic which is the most easy to resonate, and some comments, the formation of network public opinion." Network transmission has many characteristics, such as freedom, interactivity and openness. And college students with active thinking, like to accept new things. Information quality is higher and more emotional characteristics, such as a combination of both to make college students spread network public opinion and accept one of the major force of public opinion."[3]

Network public opinion supervision in colleges and universities, most schools take mainly by two ways, namely monitoring technology and the human guidance. Technology monitoring mainly rely on the school network management department to supervise the students surfing the Internet time and content. According to a timely manner, and the theory published in campus BBS and other public space is not standard, and unreasonable content management. Human guidance more focus on the student's thought, and the aspects of education. The teaching main force is mainly the relevant person in charge of each grade counselors or dormitory management, infiltration of the way in which the surface is relatively broad, can even understand his thoughts into the student individual, timely find problems and solve the problem." Technical monitoring can be implemented in the big campus. And online quickly and comprehensively grasping the information, is the basis of the stability of the campus work. Human guidance pay more attention to student's 
ideological and political education, from a long-term point of view to achieve the purpose of better." ${ }^{\text {[4] }}$

\section{The characteristics of university network public opinion and the formation process}

\subsection{The universality and directness of the influence}

Network information dissemination is different from the original medium, it broke the boundaries of time and space. The transmission speed is fast and difficulty to control, which can make all kinds of information spread quickly in a short time, and makes the impact of an event will be more extensive. Its effect will be more direct. As the main force of the university network public opinion, the students and teachers not only belong to the individual of the school, but also belong to the individual of the society. They accept the information from all aspects of society, especially in the new media technology highly developed today, such as Weibo, QQ Zone, and the circle of friends can be route of transmission of information, everyone became a publisher of network information from the media. It makes the influence of network public opinion with each subject in colleges and universities network spreading quickly, and the theme of this information is free. When we solve this problem, university network public opinion formed in a certain, and have a direct impact on people.

\subsection{The uncertainty and provocativeness of the content}

Source of network information resources is very extensive, including the authority of the state authorities issued news, and the unconfirmed grapevine. Intermingled information is probably the way to spread. Due to the network anonymity of the space, a lot of people in the spread of the network information do not identify because individual mislead society and the manufacture of false information. It is a huge challenge to put forward the authenticity of the contents of network public opinion. We always can see the network information is not reliable, and determine the subject of a lot of times is spontaneous casual. Moreover, it may have been some foreign anti-china forces to use with ulterior motives, distorting the fact that China's development intensified social contradictions. Once this type of information through social media, the school network space is bound to set off a frenzy in the university network public opinion. On the one hand, these unconfirmed news covers the truth of certain events. On the other hand, it is very unfavorable to the university network public opinion supervision and management. A youth of college students is lack of social experience and vulnerable to the exaggerated expression fan which could produce ultra mass incidents.

\subsection{The sexual activity and deviation of the main force}

First of all, the main force of the university network public opinion transmission is college students and teachers. This subject has certain professional knowledge and skills and cultural literacy. Compared with other social groups, they are more willing to express their opinions and feelings in the cyberspace, or for a specific event to guide public opinion. And they were also quite creative, keep curiosity to new things and has a certain social sense of responsibility. But it is not literally disinformation tale, which can according to specific events to respond in a timely manner. The main force of the university network public opinion is more active than the force of the social network public opinion. But the students are relatively lack of social experience and views on certain issues in-depth and thorough, not exploring the essence through the formal appearance of things, and individuals may be a little discontent in student life, by some easy to arouse resonance of social practice. It is easy to impulse to express some irresponsible view influence public opinion toward, concealing the truth, even causing large-scale network violence.

From the production to appease, university network public opinion is some regularity in the process. First, there is a news, whether it is a society of common concern to the news or a campus news to the students' interests, someone will immediately release in personal Weibo or your circle of friends, and some activists in university network public space may be communicated on this event. Everyone's attention gradually increase. On this specific question and in the process of comment, there will be more and more people to gradually join the discussion. This timely network information interaction, enables various views and opinions expressed quickly. With more widely and deeply discuss, network public opinion can get more concentrated reflection. At this stage, in order to solve this hot news everyone's attitude will be more enthusiasm, with all kinds of true or false news beginning to impact the network space, because in the network anonymity of the space, a lot of irresponsible remarks have been released from may to a certain extent, prevents the truth. But with the development of the incident, the official media published objective truth, guide the public opinion direction, and subside the hot spots. The elements of "network public opinion in mature stage after the full impact of communication, a new change, its features are: the interests of the main demands are met, or to clarify the truth, Internet users focus gradually shift, reduced the volume of Posting, begin to pay close attention to the new hot spot." ${ }^{[5]}$ University network public opinion supervision and management according to the laws of the public opinion of emergence and development process to explore, in the initial hot spot, prepare, at the time of information overflow combing opinion immediately, to guide, after the event slows should also be timely education was carried out on the subject of public opinion. 


\section{From the perspective of media literacy to strengthen the management of the university network public opinion supervision measures}

\subsection{To build a good opinion leader team}

Opinion leaders point out that in interpersonal communication network often provide information for others, opinions, comments, and influence of the "active" to others. They spread the information to the masses, the formation of two levels of transmission of information. This kind of person is active in the network space, to a large extent affects the university network public opinion direction." According to Tsinghua university in 2003 and 2003 the two, according to the results of questionnaire survey on the campus BBS BBS activities, those who are most like "opinions" in the discussion, accounts for only $18.4 \%$ of students", published the article discussion of "only $3.1 \%$ ", read the article "64.1\%" [6] this fully shows that most people are not willing to give air to her comments directly on the BBS, by watching other people think about this event. At this time, the role of opinion leaders began to emerge, and their words are affecting the nearly twenty percent. It is not willing to participate in discussions and express their opinions. Combining the actual requirement of the school. Therefore, to build a good opinion leader team for strengthening network public opinion supervision and management in colleges and universities has an indispensable role. This is actually a model of college students' autonomous organization and management, students concerned topic by the students to explore, to form students' point of view, to suppress or constraint, after all, not blindly the long term, through a purposeful, but not so clear the role of opinion leaders to guide public opinion towards is actually use "open" way to solve the problem of public opinion supervision and management of colleges and universities.

\subsection{Changing the concept of university network public opinion supervision and management}

In the past, network public opinion supervision relied mainly on the sensitive words to evade or have limits on some sites, such as mandatory method, limited students' surf the Internet time, by some technical means testing students visit the web site to supervise the "wall", etc. Internet age has come. However, through various channels to spread, the network information has revealed to us, just rely on technical methods of limit has gone far can not adapt to the present open, democracy, mutual aid network society. Contemporary college students are very active on the Internet, "behind the network public opinion is the student independent behavior, civil rights consciousness contains the student groups. Students Internet users actually is not content to simply go on the Internet for entertainment and vent to speak, but to take part in the social reality in the form of this life and public affairs." ${ }^{[7]}$ The network public opinion supervision and management, should profoundly understand this truth. The network public opinion information resources value is far more than tough to cut off the route of transmission of information more effectively. So changing the idea of university network public opinion supervision and management, from the "wall" gradually to "thin", efficient use of network public opinion, to achieve better education effect.

\subsection{Open the media literacy education of specialized courses}

Media literacy refers to the ability of people to use media and understanding, critical media transmission information. In the process of college network public opinion development we see not hard, someone has high media literacy can timely the integrity of the information analysis in the event from the media, identify false information, make sure you are not some ulterior motives influence of speech, produce extreme opinions and views, can avoid network of false information to the impact of the body. So media literacy education in colleges and universities to carry out the specialized course is the hope can through professional guidance, make college students with false network information has certain immune ability, which can truly correct use of the resources of network this big treasure, communicate with more people discuss views and opinions on specific social hot spot to make themselves more wisely and critical."The formation and operation process of public opinion, is the communication process of people's thoughts, feelings, the network public opinion is also the ideological and political education work is one of the most important gripper. " ${ }^{[8]}$ through developing common media literacy education in schools, make the most of the students all have higher media literacy, on the one hand, reduce the burden of university network public opinion supervision and management work, on the other hand we also work for ideological and political education is an important content.

\section{CONCLUSION}

Everybody in the current social live in a world surrounded by the media, we are affected by the information conducted by the media every hour and moment. In the college students who have not formed its own system of world outlook and methodology is not different from adults, their cognitive and feelings of the society is in the formation period, it is easy to be influenced by the multimedia information, whether it is positive or negative, it will leave a deep imprint in the course of their physical and mental development. We study the education problem of teenagers in the present can not only research in the book education, but also explore new rules constantly with the changes of our times. The new media era has arrived, it is more and 
more important to strengthen the network public opinion supervision and management by drawing on the theory and practice of media literacy education in the west and doing the research of China's teenagers' media literacy problems.

\section{Acknowledgements}

This research is supported by 2014 Social sciences and Technology in hebei province project "Micro era environment with the ideological and political education for College students" (project number:2014040316)

\section{References}

[1]Srills\&Strategies for Media Education by Elizabenth Thoman from Center of Media literacy of USA. From Bi $\mathrm{Yu}$. The Theory and Practice of Media Literacy Education Abroad[J]. The press,p34,2008(2).
[2]Pan Qingquan,Wei Huimin. Try to Discuss the Characteristics the Influence and the Effective Utilization of College Network Public Opinion,[J]. School party construction and ideological education,p82,2012(10).

[3] Yan Bing, Guo Pei, Zhang Yuhua. The College Network Public Opinion and Ideological and Political Education Work Measures [J]. Continue to education research, p113.2009(7).

[4][7]Fang Ran. To Explore the University Network Public Opinion Management Present Situation and the Governance Mode.[J]. Hei Longjiang province advanced research. P42,p44,2013(4).

[5][8] Li Qijian. Understanding and Thinking on the College Network Public Opinion[J]. Media.p69,2014 (3).

[6]Zhang Zhongping. The Strategic Research of University Network Public Opinion Management.[J].The university library work, p21,2011 (6). 